\title{
Amplifications of EGFR gene and protein expression of EGFR, Her-2/neu, c-kit, and androgen receptor in phyllodes tumor of the prostate
}

Xiaoyan Wang ${ }^{1}$, Timothy D Jones ${ }^{1}$, Shaobo Zhang ${ }^{1}$, John N Eble ${ }^{1}$, David G Bostwick ${ }^{2}$, Junqi Qian ${ }^{2}$, Antonio Lopez-Beltran ${ }^{3}$, Rodolfo Montironi ${ }^{4}$, John J Harris ${ }^{1}$ and Liang Cheng ${ }^{1,5}$

${ }^{1}$ Department of Pathology and Laboratory Medicine, Indiana University School of Medicine, Indianapolis, IN, USA; ${ }^{2}$ Bostwick Laboratories, Richmond, VA, USA; ${ }^{3}$ Department of Pathology, Cordoba University, Cordoba, Spain; ${ }^{4}$ Institute of Pathological Anatomy and Histopathology, School of Medicine, Polytechnic University of the Marche Region (Ancona), United Hospitals, Ancona, Italy and ${ }^{5}$ Department of Urology, Indiana

University School of Medicine, Indianapolis, IN, USA

Phyllodes tumor of the prostate is a rare neoplasm with an unpredictable clinical behavior. It may undergo early recurrence with sarcomatous transformation or may even metastasize. Because targeted therapies have shown great success against several malignancies, there is hope that these same therapies may show similar promise in the treatment of other neoplasms. This study was undertaken to investigate both amplification of the epidermal growth factor receptor (EGFR) gene by fluorescence in situ hybridization and the overexpression of EGFR, Her-2/neu, CD117 (c-kit), and androgen receptor by immunohistochemical staining in a series of 11 phyllodes tumors of the prostate. In the stromal elements, EGFR gene amplification was present in four of 11 tumors and polysomy chromosome 7 was present in two of 11 tumors. No amplification was present in the epithelial components. Only one of 11 tumors had polysomy of chromosome 7 in the epithelial components. Immunohistochemically, in the stromal components, EGFR expression was demonstrable in four of 11 tumors and androgen receptor was demonstrated in six of 10 tumors. Neither Her-2/neu nor c-kit expression was seen in the stromal components of any of the 11 tumors. In the epithelial components, EGFR expression was present in all 11 tumors with strong staining in the basal cell layers and weak or no staining in luminal epithelium; androgen receptor expression was seen in seven of 10 tumors; Her-2/neu was weakly positive in four of 11 tumors; and c-kit expression was present focally and weakly in two of 11 cases with only $2-5 \%$ of cells staining. The highest staining intensity and the highest percentage of positively staining cells were seen with EGFR immunostaining in both the stromal and epithelial (mainly basal cells) components. Androgen receptor staining showed the next highest staining intensity and percentage of positive cells in both components. Her-2/neu and c-kit were only weakly or infrequently expressed in the epithelial components of prostatic phyllodes tumors. Our data indicate that EGFR and androgen receptor are frequently and strongly expressed in both epithelial and stromal components of prostatic phyllodes tumors. EGFR gene amplification is frequently present in prostatic phyllodes tumors and may account for one of the mechanisms leading to protein overexpression in some but not all cases. Anti-EGFR and/or antiandrogen agents may be potentially useful for management of patients with tumors expressing EGFR and/or androgen receptor.

Modern Pathology (2007) 20, 175-182. doi:10.1038/modpathol.3800724; published online 22 December 2006

Keywords: prostate; phyllodes tumor; sarcoma; EGFR; Her-2/neu; fluorescence in situ hybridization

Correspondence: Dr L Cheng, MD, Department of Pathology and Laboratory Medicine, Indiana University School of Medicine, 350 West 11th Street, Clarian Pathology Laboratory, Room 4010, Indianapolis, IN 46202, USA.

E-mail: lcheng@iupui.edu

Received 13 April 2006; revised 29 September 2006; accepted 12 October 2006; published online 22 December 2006
Phyllodes tumor of the prostate is a rare biphasic neoplasm. Like its breast counterpart, it consists of an epithelial component forming complex glands in a cellular stroma. ${ }^{1}$ Current knowledge of clinicopathologic features, biological behavior, and treatment of this tumor is derived from a limited number of small series and case reports. Although the 
majority of phyllodes tumor are cured surgically, some have recurred locally and some have metastasized. So far, no single morphologic finding has been a reliable predictor of clinical behavior. The genetics of the prostatic phyllodes tumor is largely unknown. Using loss of heterozygosity analysis, we demonstrated that both the epithelial and stromal components of prostatic phyllodes tumors appear to be true neoplastic proliferations with different clonal origins. ${ }^{2}$

Accumulating evidence shows that the epidermal growth factor receptor (EGFR) is involved in the pathogenesis and progression of many malignancies. A recent study revealed that amplifications of the EGFR gene are common and are associated with tumor progression in phyllodes tumors of the breast. ${ }^{3}$ However, a similar analysis has not been performed on prostatic phyllodes tumor. In phyllodes tumors of the breast, c-kit (CD-117) expression is correlated with increased tumor grade and may be useful in predicting recurrent disease. ${ }^{4} \mathrm{Her}-2 /$ neu is overexpressed in $20-30 \%$ of breast cancers and this overexpression is associated with a poor prognosis. Furthermore, since targeted therapies have shown great success against several malignancies (eg STI571 in gastrointestinal stromal tumor, herceptin in breast cancer, cetuximab in advanced colorectal and lung cancers, and antiandrogens in prostate cancer), ${ }^{5-9}$ there is hope that these same therapies may show similar promise in the treatment of other neoplasms, such as phyllodes tumor of the prostate.

This study was undertaken to investigate EGFR gene amplification by fluorescence in situ hybridization (FISH) and to examine the protein expression of EGFR, Her-2/neu, c-kit, and androgen receptor by immunohistochemical staining in a series of 11 cases of phyllodes tumor of the prostate. Additionally, this study addresses the correlation between EGFR gene amplification and protein expression. Ultimately, this investigation is designed to provide further insight into the molecular pathogenesis of phyllodes tumor of the prostate and to define potential therapies for this rare neoplasm.

\section{Materials and methods}

\section{Patients}

A total of 11 cases of prostatic phyllodes tumor were obtained from a period of 1982 to 2003 from Indiana University (Indianapolis, IN, USA); Bostwick Laboratories (Richmond, VA, USA); Cordoba University (Cordoba, Spain); and Polytechnic University of the Marche Region (Ancona, Italy). The medical records and pathologic findings were reviewed. Formalin-fixed, paraffin-embedded tissue was available for all cases. Hematoxylin and eosinstained sections were examined. The patients' ages ranged from 25 to 88 years with a mean age of 53 years, and all presented with urinary obstruction or painless hematuria. Four patients were diagnosed by transurethral resection and seven by retropubic prostatic enucleation or radical prostatectomy. Five of the patients had no recurrence. One had multiple recurrences, occurring at 1 month, 6 months, and 10 years after diagnosis. Following these three recurrences, sarcomatous transformation occurred in this patient 11 years after the original diagnosis. Sarcomatous transformation was defined as stroma with markedly increased cellularity, pleomorphism, mitotic figures, necrosis, and stromal overgrowth in accordance with World Health Organization (WHO) criteria and with Epstein's group at the Johns Hopkins Medical Institutions. ${ }^{10-12}$ Metastasis to the lung in two patients and to the abdominal wall in one patient occurred 2 years after diagnosis. No follow-up data were available in two cases.

\section{Tissue Preparations and FISH for EGFR}

FISH was performed as previously described. ${ }^{13,14}$ Four- $\mu$ m-thick sections of the prostatic phyllodes tumors were cut from paraffin blocks. The slides were deparaffinized with two washes of xylene, $15 \mathrm{~min}$ each, and were subsequently washed twice with absolute ethanol, $10 \mathrm{~min}$ each, and then airdried in the hood. The slides were then treated in $0.1 \mathrm{mM}$ citric acid ( $\mathrm{pH}$ 6.0) (Zymed, CA, USA) at $95^{\circ} \mathrm{C}$ for $10 \mathrm{~min}$ and were rinsed in distilled water for $3 \mathrm{~min}$. This step was followed by a wash of $2 \times$ SSC (standard saline citrate) for $5 \mathrm{~min}$. Digestion of the tissue was performed by applying $0.4 \mathrm{ml}$ of pepsin $(5 \mathrm{mg} / \mathrm{ml}$ in $0.9 \% \mathrm{NaCl}, \mathrm{pH} 1.5$ ) (Sigma, St Louis, MO, USA) at $37^{\circ} \mathrm{C}$ for $40 \mathrm{~min}$. The slides were rinsed with distilled water for $3 \mathrm{~min}$, then washed with $2 \times$ SSC for $5 \mathrm{~min}$, and air dried.

FISH was performed with centromeric $\alpha$-satellite DNA probes for chromosome 7 (Centromeric Enumeration Probe, CEP 7, Spectrum Green) and with probes for the EGFR gene at chromosome $7 \mathrm{p} 12$ (EGFR, Spectrum Orange). All the probes were from Vysis (Vysis, Downers Grove, IL, USA) and were diluted with $t$ DenHyb2 (Insitus, Albuquerque, NM, USA) in a ratio of 1:50. Five microliters of diluted probe were applied to each slide in the reduced light condition. The slides were then covered with a $22 \times 22 \mathrm{~mm}$ coverslip and sealed with rubber cement. Denaturation was achieved by incubating the slides at $80^{\circ} \mathrm{C}$ for $10 \mathrm{~min}$ in a humidified box and then hybridized at $37^{\circ} \mathrm{C}$ over night. The cover slips were removed and the slides were washed extensively with two $45^{\circ} \mathrm{C}$ pre-warmed $0.1 \times$ SSC/1.5 M urea, $20 \mathrm{~min}$ for each, followed by a wash with $2 \times$ SSC for $20 \mathrm{~min}$ and with $2 \times$ SSC/ $0.1 \%$ NP40 for $10 \mathrm{~min}$ at $45^{\circ} \mathrm{C}$. The slides were further washed with room temperature $2 \times \mathrm{SSC}$ for $5 \mathrm{~min}$. The slides were air dried and counterstained with $10 \mu \mathrm{l}$ DAPI (Insitus, Albuquerque, NM, USA). They were then covered with coverslips and sealed with nail polish. The slides were examined using a Zeiss Axioplan 2 microscope (ZEISS, Göttingen, Germany) with the 
following filters: SP-100 DAPI, FITC MF-101 for spectrum green (CEP 7) and Gold 31003 for Spectrum orange $(E G F R)$ from Chroma (Chroma, Brattleboro, VT, USA). The images were acquired with a CCD camera and analyzed with MetaSystem Isis Software (MetaSystem, Belmont, MA, USA). Four sequential focus stacks with $0.4 \mu \mathrm{m}$ intervals were acquired and then integrated into a single image in order to reduce thickness related artifacts.

\section{FISH Analysis for EGFR}

For each slide, 75 to 100 nuclei were scored for signals from both DNA probes under the fluorescence microscope with magnification of $\times 1000$ in both neoplastic stroma and closely adjacent epithelial cells. Signals from nonoverlapping nuclei were included in the counts. Two signals of the same size in close proximity, not connected by a link, were counted as two signals. A diffuse signal was regarded as one signal if it was contiguous and within an acceptable boundary. Two small signals connected by a visible link were counted as one signal. Overlapping nuclei and nuclei with uncertain signal were not included in the counts. According to Perry's criteria, ${ }^{15}$ EGFR amplification was defined as over $5 \%$ of the cells with more than four EGFR signals and the ratio of EGFR/CEP7 over 2. Polysomy was defined as over $5 \%$ of the cells with more than two signals for both probes and the EGFR/CEP7 ratio below 2. For each FISH preparation, known positive and negative cells were used as control. The preparation is valid if more than $90 \%$ of the cells showed bright signals.

Seven cases of benign prostatic hyperplasia (BPH) were also analyzed.

\section{Immunohistochemical Study for EGFR, c-kit, Her-2/neu, and Androgen Receptor}

Immunostaining for EGFR, c-kit, Her-2/neu, and androgen receptor was performed on the paraffinembedded tissue sections using the peroxidaselabeled streptavidin-biotin method. Five- $\mu$ m-thick tissue sections from each patient were used for immunohistochemical staining. Sections were deparaffinized in xylene for $5 \mathrm{~min}$ and then rehydrated through graded ethanol solutions to distilled water. Antigen retrieval was performed by heating sections for $15 \mathrm{~min}$. Endogenous peroxidase was blocked by incubation in $3 \% \mathrm{H}_{2} \mathrm{O}_{2}$ for $5 \mathrm{~min}$. Tissue sections were incubated with primary antibodies against EGFR, c-kit, Her-2/neu, and androgen receptor (antibodies against EGFR, Her-2/neu, and androgen receptor from DAKO Corporation, Carpinteria, CA, USA; antibody against c-kit from Calbiochem, San Diego, CA, USA) for $10 \mathrm{~min}$, followed by biotinylated secondary antibody and peroxidase-labeled streptavidin. 3,3-diaminobenzidine was used as the chromogen. The extent of staining was evaluated by visual examination microscopically. Each section was scanned at low magnification and staining of EGFR (cytoplasmic and membranous staining), c-kit (cytoplasmic and membranous staining), Her-2/neu (membranous staining), and androgen receptor (nuclear staining) were scored by evaluating the percentage of tumor cells staining positively (\%) and the intensity of staining. Staining intensity was defined as negative $(0)$, weak $(1+)$, moderate $(2+)$, or strong $(3+) .{ }^{16}$ Overexpression of EGFR was defined as more than $10 \%$ of tumor cells with positive staining.

\section{Results}

\section{FISH Study for EGFR Gene Amplification}

In the stromal components, EGFR gene amplification was present in four of 11 cases and polysomy was present in two of 11 cases (Table 1, Figure 1). Cases 1, 5, 7, and 8 showed more than four EGFR signals and an EGFR/CEP7 ratio greater than 2 in 18, 6,37 , and $8.5 \%$ of cells, respectively. Cases 3 and 11 had more than two signals for both EGFR and CEP7 with EGFR/CEP7 ratios of 1-2 in 6 and $30 \%$ of cells, respectively. In contrast, in the epithelial components, no EGFR amplification was present in any of the 11 cases and polysomy was only observed in one of 11 cases. Case 1 had $9 \%$ of epithelial cells with more than two signals for both EGFR and CEP7 with an EGFR/CEP7 ratio of 1.1 .

None of seven cases of BPH showed EGFR amplification or polysomy in either stromal or epithelial component.

\section{Immunohistochemistry Study for EGFR, HER-2/neu, c-kit, and AR}

The immunohistochemical staining results are summarized in Table 2. In the stromal components, EGFR expression was demonstrated in four of 11 tumors and androgen receptor staining was demonstrated in six of 10 cases. Neither Her-2/neu nor c-kit expression was demonstrable in the stromal components of any of 11 tumors. In the epithelial components, EGFR expression was demonstrable in all 11 tumors with strong staining in the basal cells and weak or no staining in the luminal epithelium (Figure 1e and f). Androgen receptor expression was demonstrated in seven of 10 tumors; Her-2/neu was weakly positive in four of 11 tumors $(1+$ staining in $2-60 \%$ cells); and c-kit expression was detected very focally and weakly in two of 11 tumors $(1+$ staining in $2-5 \%$ of cells). The highest staining intensity and highest percentage of positively staining cells was seen with EGFR immunostaining in both the stromal and epithelial (mainly basal cells) components. Androgen receptor staining showed the next highest staining intensity and percentage of positive cells in both components. Her-2/neu and c-kit were only weakly or infrequently expressed in 
Table 1 FISH analysis of the EGFR amplification and polysomy in the stromal and epithelial components of phyllodes tumors of the prostate

\begin{tabular}{|c|c|c|c|c|c|c|c|c|}
\hline \multirow[t]{2}{*}{ Case } & \multicolumn{4}{|c|}{ Stroma } & \multicolumn{4}{|c|}{ Epithelium } \\
\hline & $E G F R>4(\%)$ & EGFR/CEP7 & EGFR, CEP7> $2(\%)$ & $E G F R / C E P 7^{\mathrm{a}}$ & $E G F R>4(\%)$ & EGFR/CEP7 & $E G F R, C E P 7>2(\%)$ & $E G F R / C E P 7^{\mathrm{a}}$ \\
\hline 1 & 18 & 2.5 & 4 & 1.25 & 12.1 & 1.57 & 9 & 1.1 \\
\hline 2 & 0 & 0 & 0 & 0 & 0 & 0 & 2 & 1.3 \\
\hline 3 & 22 & 1.7 & 6 & 1.6 & 3 & 1.4 & 1 & 1.3 \\
\hline 4 & 1 & 3.5 & 1 & 1.33 & 0 & 0 & 0 & 0 \\
\hline 5 & 6 & 2.5 & 2 & 1 & 1.6 & 2 & 0 & 0 \\
\hline 6 & 1 & 1.2 & 1 & 1.3 & 0 & 0 & 0 & 0 \\
\hline 7 & 37 & 2.4 & 2 & 1.25 & 0 & 0 & 0 & 0 \\
\hline 8 & 8.5 & 3.1 & 2 & 1.3 & 1.2 & 2.5 & 2 & 1.2 \\
\hline 9 & 0 & 0 & 0 & 0 & 0 & 0 & 2 & 1 \\
\hline 10 & 7 & 1.3 & 3 & 1.5 & 0 & 0 & 1 & 1 \\
\hline 11 & 21 & 1.3 & 30.4 & 1.1 & 0 & 0 & 0 & 0 \\
\hline
\end{tabular}

Light grey shading indicates amplification: $>5 \%$ of cells have $>4$ EGFR signals and EGFR/CEP7 $>2$.

Dark grey shading indicates polysomy: $>5 \%$ of the cells have $>2$ signals for both EGFR and CEP7, and EGFR/CEP7 $<2$.

${ }^{a}$ EGFR amplification was defined as more than $5 \%$ of the cells showed more than 4 EGFR signals and the EGFR/CEP7 ratio is greater than 2. The EGFR polysomy was defined as more than $5 \%$ of the cells showed more than two signals for both EGFR and CEP7 and the EGFR/CEP7 ratio is smaller than 2. The FISH results were presented as percentage of positive cells and the EGFR/CEP7 ratio.
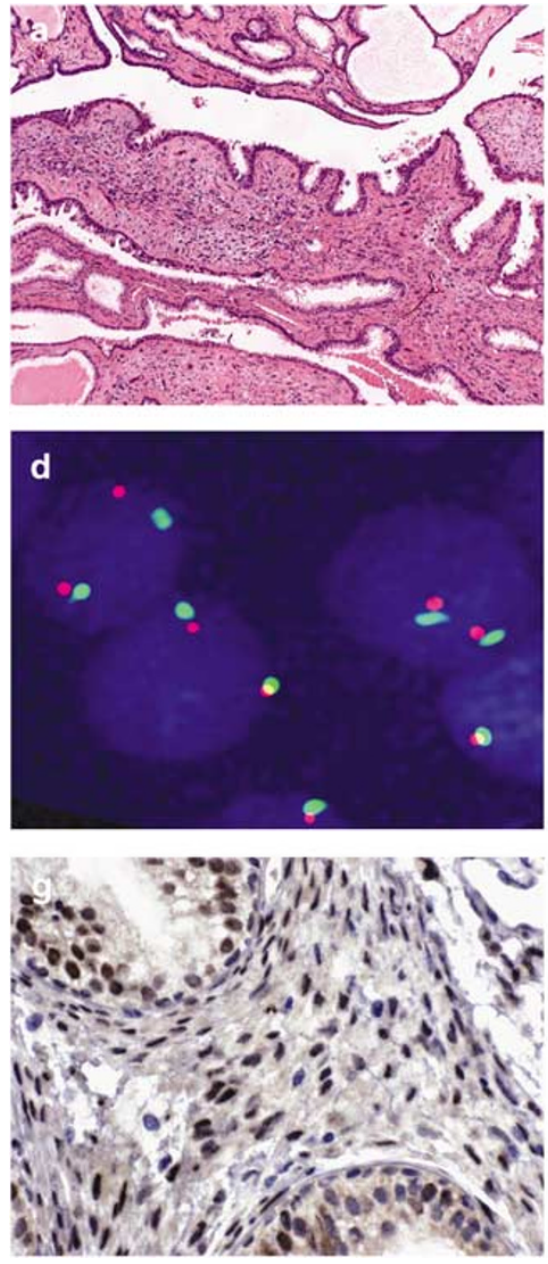
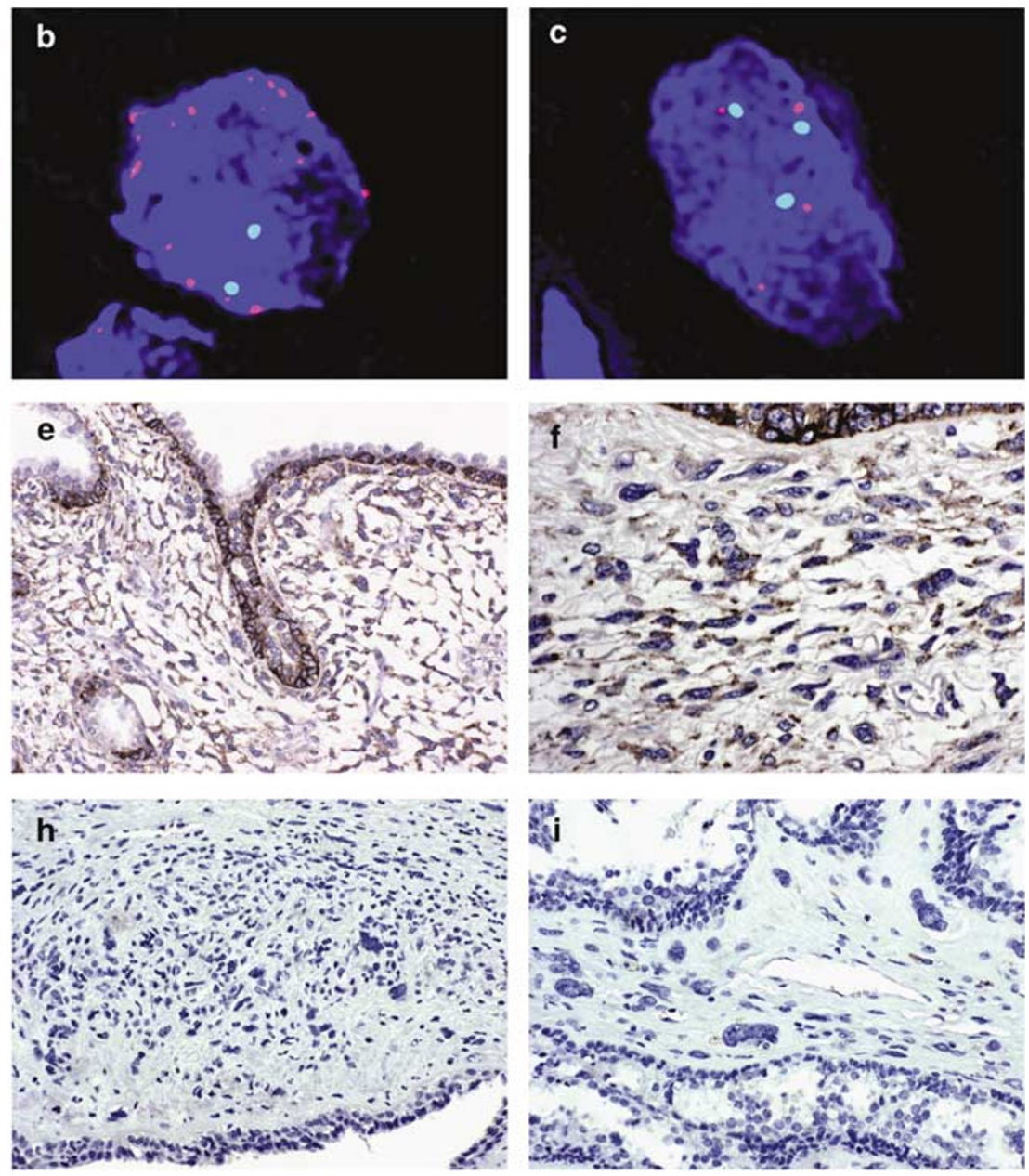

Figure 1 Phyllodes tumor of the prostate. The prostate phyllodes tumor consists of epithelial component and cellular stroma forming a leaf-like structure (a). The dual color FISH showed the stroma cells with multiple copies of EGFR (red) and two copies of CEP7 (green) and the EGFR/CEP7 ratio is greater than 2 (amplification) (b). Some of the stroma cells also showed the increased number for both EGFR and CEP7 signals and the ratio of EGFR/CEP7 is small than 2 (polysomy) (c). The epithelium closely adjacent to the cellular stromal area showed a typical normal pattern of EGFR/CEP7 (d). The EGFR (e-f) and androgen receptor (g) positive staining for the stromal cells and epithelial cells of phyllodes tumor, with EGFR staining mainly in basal cell layers of epithelium (e). The stromal components showed Her-2/neu (h) and c-kit (i) negative immunostaining. 
Table 2 Immunohistochemistry of the EGFR, androgen receptor, Her2/neu, and c-kit in stromal and epithelial components of phyllodes tumors of the prostate

\begin{tabular}{|c|c|c|c|c|c|c|c|c|c|c|c|c|c|c|c|c|}
\hline \multirow[t]{3}{*}{ Case } & \multicolumn{4}{|c|}{$E G F R^{\mathrm{a}}$} & \multicolumn{4}{|c|}{$H E R-2^{\mathrm{b}}$} & \multicolumn{4}{|c|}{ c-kit } & \multicolumn{4}{|c|}{ Androgen receptor } \\
\hline & \multicolumn{2}{|c|}{ Stroma } & \multicolumn{2}{|c|}{ Epithelium } & \multicolumn{2}{|c|}{ Stroma } & \multicolumn{2}{|c|}{ Epithelium } & \multicolumn{2}{|c|}{ Stroma } & \multicolumn{2}{|c|}{ Epithelium } & \multicolumn{2}{|c|}{ Stroma } & \multicolumn{2}{|c|}{ Epithelium } \\
\hline & Intensity & $\%$ & Intensity & $\%$ & Intensity & $\%$ & Intensity & $\%$ & Intensity & $\%$ & Intensity & $\%$ & Intensity & $\%$ & Intensity & $\%$ \\
\hline 1 & 1 & 20 & 3 & 100 & 0 & 0 & 1 & 60 & 0 & $0^{\mathrm{c}}$ & 0 & 0 & 1 & 1 & 2 & 30 \\
\hline 2 & 0 & 0 & 3 & 98 & 0 & 0 & 0 & 0 & 0 & $0^{\mathrm{c}}$ & 1 & 2 & 2 & 30 & 2 & 40 \\
\hline 3 & 1 & 1 & 3 & 100 & 0 & 0 & 1 & 2 & 0 & $0^{\mathrm{c}}$ & 0 & 0 & 1 & 10 & 2 & 30 \\
\hline 4 & 3 & 60 & 3 & 100 & 0 & 0 & 0 & 0 & 0 & $0^{\mathrm{c}}$ & 0 & 0 & 0 & 0 & 0 & 0 \\
\hline 5 & 0 & 0 & 3 & 100 & 0 & 0 & 1 & 10 & 0 & 0 & 0 & 0 & 3 & 50 & 3 & 95 \\
\hline 6 & 0 & 0 & 3 & 100 & 0 & 0 & 0 & 0 & 0 & $0^{\mathrm{c}}$ & 0 & 0 & 0 & 0 & 0 & 0 \\
\hline 7 & 3 & 70 & 3 & 98 & 0 & 0 & 0 & 0 & 0 & 0 & 0 & 0 & 0 & 0 & 0 & 0 \\
\hline 8 & 0 & 0 & 3 & 100 & 0 & 0 & 1 & 20 & 0 & $0^{\mathrm{c}}$ & 0 & 0 & 3 & 20 & 3 & 60 \\
\hline 9 & 0 & 0 & 3 & 98 & 0 & 0 & 0 & 0 & 0 & $0^{\mathrm{c}}$ & 1 & 5 & 2 & 15 & 3 & 80 \\
\hline 10 & 0 & 0 & 3 & 95 & 0 & 0 & 0 & 0 & 0 & 0 & 0 & 0 & NA & NA & NA & NA \\
\hline 11 & 3 & 40 & 3 & 40 & 0 & 0 & 0 & 0 & 0 & 0 & 0 & 0 & 3 & 80 & 3 & 90 \\
\hline
\end{tabular}

All stains intensity graded as: $0,1+, 2+, 3+$.

NA, not applicable.

${ }^{a}$ Basal cells staining strongly positive, luminal epithelial cells staining negative or weakly positive.

${ }^{b}$ Epithelium showing weak positivity in four cases.

${ }^{\mathrm{c}}$ Focal staining in stromal mast cells, not in tumor cells.

the epithelial and stromal components of prostatic phyllodes tumors.

\section{Correlation between EGFR Protein Expression and Gene Amplification}

Both EGFR protein expression and gene amplification data were obtained on all 11 tumors. Four tumors (\#1, 4, 7, and 11) showed EGFR protein expression in the stromal components. Among these four tumors, two (\#1 and 7) showed EGFR gene amplification in the stromal components. One more (case \#11) demonstrated stromal polysomy of chromosome 7. EGFR protein overexpression was present in one tumor (\#4) where neither amplification nor polysomy was identified. Two tumors (\#5 and \#8) demonstrated EGFR gene amplification by FISH in the stromal components without showing protein expression by immunohistochemistry. One tumor (\#3) demonstrated stromal chromosome 7 polysomy, but no protein overexpression was observed. Positive immunostaining for EGFR is, thus, a poor predictor of EGFR gene amplifications. All epithelial components (11/11) showed EGFR protein overexpression (mainly basal cells) by immunohistochemistry; however, none of these components showed EGFR gene amplification by FISH. One tumor (\#1) demonstrated polysomy of chromosome 7. Thus, immunohistochemical expression of EGFR in the epithelial components does not correlate with EGFR gene amplifications.

\section{Discussion}

Phyllodes tumor of the prostate is a rare neoplasm with fewer than 60 cases reported. A variety of terms have been used to describe this entity, including atypical stromal hyperplasia, phyllodes type of hyperplasia, prostatic cystic epithelial stromal tumor, and cystosarcoma phyllodes. Patients typically present with urinary obstruction, hematuria, or dysuria with a peak incidence in the sixth and seventh decades of life. ${ }^{1,11}$ The clinical course, the immunohistochemical profile, the biologic behavior, and the most effective treatment of this unusual neoplasm have not been well characterized. In the 2004 WHO classification of tumors of urinary system and male genital organs, the tumors of specialized prostatic stroma have been divided into prostatic stromal proliferations of uncertain malignant potential (STUMP) and prostatic stromal sarcomas. ${ }^{10}$ In 1998 and 2006, Epstein's group at the Johns Hopkins Medical Institutions performed two series of clinicopathologic studies of 22 and 50 cases of specialized stromal tumor of the prostate. They used the same classifications of prostatic STUMP and stromal sarcoma based on morphologic criteria, including stromal cellularity, mitotic figures, cytologic atypia, necrosis, and stromal overgrowth. Four distinct patterns of STUMP were described: (1) stroma with scattered cytologically atypical cells (degenerative atypia); (2) hypercellular stroma; (3) extensive myxoid stroma; and (4) phyllodes type. However, they found that these four distinct histologic subtypes of STUMP do not correlate with clinical behavior or likelihood of being associated with sarcoma. ${ }^{11,12}$ Therefore, there are limitations to classification by morphology alone, as it does not always correlate with clinical outcome. Since sarcoma may arise within any grade of tumor, Bostwick et al, in a series of 23 cases, proposed to grade the phyllodes tumor into three 
categories (low grade, intermediate grade, and high grade) based on the combination of stromal cellularity, cytologic atypia, mitotic figures, and stroma to epithelium ratios. Similarly, they found that this grading system will only predict short-term outcome since these tumors usually recur and the emergence of sarcoma and metastatic disease is more frequent than previously recognized. ${ }^{1}$

In recent years, potential biomarkers have been explored to be used in conjunction with morphology to predict the behavior of many neoplasms. The EGFR superfamily consists of transmembrane growth factor tyrosine kinases that share similarities in structure and function. They include four distinct receptors (EGFR/erB-1, HER2/erB-2, HER3/ erb-3, and HER4/erb-4) and play an important role for tumor cell survival and proliferation. EGFR (EGFR, HER-1, c-erbB-1) is expressed in many human epithelial malignancies, including lung non-small-cell carcinoma of the lung and colorectal adenocarcinoma. ${ }^{17,18}$ The EGFR gene is located on chromosome 7p12-p22 and encodes a $170-\mathrm{kDa}$ glycoprotein composed of an N-terminal extracellular ligand-binding domain, a transmembrane lipophilic segment, and a C-terminal intracellular region containing a tyrosine kinase domain. ${ }^{19}$ Kersting et al showed that $19 \%$ of breast phyllodes tumors $(75 \%$ of malignant breast phyllodes tumors) exhibit EGFR immunopositivity in the stromal components. EGFR whole gene amplifications by FISH were seen in six of 57 cases (16\%) and EGFR intron 1 amplifications detected by gene dosage PCR were seen in 23 of 55 cases (42\%). For the six cases with gene amplifications by FISH, two cases had high-level whole-gene amplifications ( $>10$ copies per nucleus); the other four had low-level amplifications. They also found that EGFR overexpression was associated with progression in the phyllodes tumor of the breast. ${ }^{3}$ In this study, we demonstrated frequent and strong EGFR protein expression (four of 11 cases) in the stromal components of prostatic phyllodes tumors. One case had three recurrences before sarcoma emerged. The second case had three recurrences before subsequent abdominal wall metastasis. The other two cases had no clinical follow-up data available. Similar to the study of Kersting et al, our series demonstrated a comparable level of EGFR gene amplification by FISH in four of 11 cases. We also made an attempt to evaluate the relationship between EGFR protein expression and gene amplification. In our series, four tumors had protein overexpression by immunohistochemistry. Among these four tumors, two showed gene amplification and one case showed polysomy of chromosome 7 and the EGFR gene. Several mechanisms have been proposed to explain overexpression of EGFR, including gene amplification, activating mutations, increasing EGFR transcription, or translation causing increased mRNA and protein production, decreased protein destruction, overexpression of receptor ligands, and others., ${ }^{8,20}$ In glioblastoma, increased expression of EGFR is caused by highlevel amplification; ${ }^{20}$ whereas, in head and neck squamous cell carcinoma and in colonic adenocarcinoma, amplification does not appear to be responsible for protein overexpression. ${ }^{21,22}$ From our study, we postulate that in prostatic phyllodes tumors, gene amplification may lead to EGFR protein overexpression in some cases. Polysomy may represent 'low-level' amplification and account for increased EGFR expression in some cases. It can be argued that the strength of these correlations is diminished by the fact that only two cases have both gene amplification and protein expression (one case with $3+$ immunostaining in $60 \%$ of tumor cells, one case with $1+$ immunostaining in $20 \%$ of tumor cells). It should be kept in mind that this study sample size is small. Despite this limitation, it remains possible that gene amplification may lead to EGFR protein overexpression to some degree in some cases. Additional investigations are needed to confirm this mechanism. In addition, we also observed one case with apparent EGFR protein overexpression without gene amplification or polysomy. Amplification of regulatory CA short sequences in the intron 1 of EGFR has been proposed to be one of the mechanisms for EGFR protein overexpression in breast phyllodes tumors by some investigators. ${ }^{3}$ Further molecular studies need to be performed to define the role of intron 1 amplifications and other molecular changes in prostatic phyllodes tumors. Finally, our data suggest that therapy targeted against EGFR may be beneficial in a subset of the patients with phyllodes tumor of the prostate demonstrating EGFR overexpression and/or gene amplification.

Androgen receptor protein has a molecular weight of $11 \mathrm{kDa}$ and is encoded by the androgen receptor gene, which is located on chromosome Xq11-12. Androgen receptor belongs to the class of nuclear receptors called activated class I steroid receptors, which also include the glucocorticoid receptor, progesterone receptor, and mineralocorticoid receptor. The androgen receptor protein has three major functional domains, which include the N-terminal domain, DNA-binding domain, and the androgenbinding domain. ${ }^{23}$ Androgen, acting via the androgen receptor, is associated with the development and progression of prostatic adenocarcinoma. Antiandrogen therapy is widely used to manage metastatic prostate cancer and is increasingly used as adjuvant therapy in patients with earlier stage disease. ${ }^{24}$ Our study revealed that androgen receptor staining was frequent and strong in both the stromal components (six of 10 tumors) and in the epithelial components (seven of 10 tumors) of prostatic phyllodes tumors. Therefore, antiandrogen therapy may be worthwhile in a subset of patients with tumors expressing androgen receptors.

Human EGFR-2 (Her-2/neu, e-erbB-2) is a $185-\mathrm{kDa}$ transmembrane glycoprotein with intracellular 
tyrosine kinase activity. It is encoded by the Her-2/neu oncogene on chromosome 17q11-12. It is critical in the activation of subcellular signal transduction pathways controlling epithelial cell growth and differentiation. ${ }^{25}$ Overexpression of Her$2 /$ neu is present in a variety of carcinomas, including those of the breast, bladder, ovary, endometrium, and lung, and is generally associated with a poor prognosis. ${ }^{26-29}$ Recently, Montironi et al ${ }^{30}$ found that Her-2/neu is overexpressed in androgen independent prostate cancer and is not associated with gene amplification. In our study, Her-2/neu staining was not present in any of the stromal components, and this protein was only weakly expressed in the epithelial components in some cases. Therefore, we postulate that Her-2/neu is not involved in the pathogenesis of phyllodes tumors of the prostate. Since our sample size is small, further investigation is warranted to confirm this finding.

C-kit (CD117) is a transmembrane tyrosine kinase receptor, which is encoded by the proto-oncogene c-kit on chromosome 4q11-q12. C-kit has been shown to be involved in many physiological and pathological processes, including hematopoiesis and oncogenesis. ${ }^{31}$ In a tissue microarray study of mammary phyllodes tumors by Tan et al, ${ }^{4}$ c-kit immunoreactivity was present in 66\% (175 of 267) and $6 \%$ (17 of 273) of epithelial and stromal components, respectively. Sawyer et $a l^{32}$ found c-kit stromal overexpression in five of 10 malignant breast phyllodes tumors and in one of 20 benign breast phyllodes tumors, and found patchy epithelial membrane staining within the phyllodes tumors. Stromal c-kit protein expression was associated with tumor grade and may be useful in predicting recurrent disease. However, in our series of 11 cases of prostatic phyllodes tumors, c-kit expression was not identified in the stroma and was only weakly and infrequently expressed in the epithelial components $(2-5 \%$ of cells with weak staining intensity). While c-kit is frequently expressed in the malignant breast phyllodes tumors, it is possible that the prostatic counterpart has a somewhat different pathogenesis that does not involve overexpression of this protein. Alternatively, the different results obtained in breast and prostatic phyllodes tumors in regards to c-kit expression may be a reflection of our small sample size and of the fact that our series does not include cases with coexisting sarcoma. Our limited data suggest that c-kit does not appear to play a role in the development of phyllodes tumors of the prostate. Further investigation is needed to clarify the role of c-kit in pathogenesis of this neoplasm.

In summary, our data indicate that EGFR and androgen receptor are frequently and strongly expressed in both the epithelial and stromal components of prostatic phyllodes tumors. EGFR amplification is present in some cases of phyllodes tumor and may account for protein overexpression in some but not all cases. Anti-EGFR (cetuximab) and/or antiandrogen agents may be potentially useful for management of patients with tumors expressing EGFR and/or androgen receptor.

\section{References}

1 Bostwick DG, Hossain D, Qian J, et al. Phyllodes tumor of the prostate: long-term followup study of 23 cases. J Urol 2004;172:894-899.

2 McCarthy RP, Zhang S, Bostwick DG, et al. Molecular genetic evidence for different clonal origins of epithelial and stromal components of phyllodes tumor of the prostate. Am J Pathol 2004;165:1395-1400.

3 Kersting C, Kuijper A, Schmidt H, et al. Amplifications of the epidermal growth factor receptor gene (egfr) are common in phyllodes tumors of the breast and are associated with tumor progression. Lab Invest 2006; 86:54-61

4 Tan PH, Jayabaskar T, Yip G, et al. p53 and c-kit (CD117) protein expression as prognostic indicators in breast phyllodes tumors: a tissue microarray study. Mod Pathol 2005;18:1527-1534.

5 Demetri GD. Identification and treatment of chemoresistant inoperable or metastatic GIST: experience with the selective tyrosine kinase inhibitor imatinib mesylate (STI571). Eur J Cancer 2002;38(Suppl 5):S52-S59.

6 Slamon DJ, Leyland-Jones B, Shak S, et al. Use of chemotherapy plus a monoclonal antibody against HER2 for metastatic breast cancer that overexpresses HER2. N Engl J Med 2001;344:783-792.

7 Meyerhardt JA, Mayer RJ. Systemic therapy for colorectal cancer. N Engl J Med 2005;352:476-487.

8 Baselga J, Arteaga CL. Critical update and emerging trends in epidermal growth factor receptor targeting in cancer. J Clin Oncol 2005;23:2445-2459.

9 Loblaw DA, Mendelson DS, Talcott JA, et al. American Society of Clinical Oncology recommendations for the initial hormonal management of androgen-sensitive metastatic, recurrent, or progressive prostate cancer. J Clin Oncol 2004;22:2927-2941.

10 Eble JN, Sauter G, Epstein JI, et al. World Health Organization Classification of Tumours: Pathology and Genetics of Tumours of the Urinary System and Male Genital Organs. IARC Press: Lyon, 2004.

11 Gaudin PB, Rosai J, Epstein JI. Sarcomas and related proliferative lesions of specialized prostatic stroma: a clinicopathologic study of 22 cases. Am J Surg Pathol 1998;22:148-162.

12 Herawi M, Epstein JI. Specialized stromal tumors of the prostate: a clinicopathologic study of 50 cases. Am J Surg Pathol 2006;30:694-704.

13 Brunelli M, Eble JN, Zhang S, et al. Eosinophilic and classic chromophobe renal cell carcinomas have similar frequent losses of multiple chromosomes from among chromosomes $1,2,6,10$, and 17 , and this pattern of genetic abnormality is not present in renal oncocytoma. Mod Pathol 2005;18:161-169.

14 Cossu-Rocca P, Eble JN, Delahunt B, et al. Renal mucinous tubular and spindle carcinoma lacks the gains of chromosomes 7 and 17 and losses of chromosome $\mathrm{Y}$ that are prevalent in papillary renal cell carcinoma. Mod Pathol 2006;19:488-493.

15 Perry A, Kunz SN, Fuller CE, et al. Differential NF1, p16, and EGFR patterns by interphase cytogenetics (FISH) in malignant peripheral nerve sheath tumor 
(MPNST) and morphologically similar spindle cell neoplasms. J Neuropathol Exp Neurol 2002;61: 702-709.

16 Tsao MS, Sakurada A, Cutz JC, et al. Erlotinib in lung cancer-molecular and clinical predictors of outcome. N Engl J Med 2005;353:133-144.

17 Hirsch FR, Varella-Garcia M, Bunn Jr PA, et al. Epidermal growth factor receptor in non-small-cell lung carcinomas: correlation between gene copy number and protein expression and impact on prognosis. J Clin Oncol 2003;21:3798-3807.

18 Ooi A, Takehana T, Li X, et al. Protein overexpression and gene amplification of HER-2 and EGFR in colorectal cancers: an immunohistochemical and fluorescent in situ hybridization study. Mod Pathol 2004; 17:895-904.

19 Cohen S, Ushiro H, Stoscheck C, et al. A native 170,000 epidermal growth factor receptor-kinase complex from shed plasma membrane vesicles. J Biol Chem 1982;257:1523-1531.

20 Tripp SR, Willmore-Payne C, Layfield LJ. Relationship between EGFR overexpression and gene amplification status in central nervous system gliomas. Anal Quant Cytol Histol 2005;27:71-78.

21 Mrhalova M, Plzak J, Betka J, et al. Epidermal growth factor receptor-its expression and copy numbers of EGFR gene in patients with head and neck squamous cell carcinomas. Neoplasma 2005;52: 338-343.

22 Layfield LJ, Bernard PS, Goldstein NS. Color multiplex polymerase chain reaction for quantitative analysis of epidermal growth factor receptor genes in colorectal adenocarcinoma. J Surg Oncol 2003;83: 227-231.

23 Peterziel H, Mink S, Schonert A, et al. Rapid signalling by androgen receptor in prostate cancer cells. Oncogene 1999;18:6322-6329.
24 Noordzij MA, Bogdanowicz JF, van Krimpen C, et al. The prognostic value of pretreatment expression of androgen receptor and bcl-2 in hormonally treated prostate cancer patients. J Urol 1997;158:1880-1885.

25 Yamamoto T, Ikawa S, Akiyama T, et al. Similarity of protein encoded by the human c-erb-B-2 gene to epidermal growth factor receptor. Nature 1986;319: 230-234.

26 Slamon DJ, Godolphin W, Jones LA, et al. Studies of the HER-2/neu proto-oncogene in human breast and ovarian cancer. Science 1989;244:707-712.

27 Onn A, Correa AM, Gilcrease M, et al. Synchronous overexpression of epidermal growth factor receptor and HER2-neu protein is a predictor of poor outcome in patients with stage I non-small cell lung cancer. Clin Cancer Res 2004;10:136-143.

28 Mayr D, Kanitz V, Amann G, et al. HER-2/neu gene amplification in ovarian tumours: a comprehensive immunohistochemical and FISH analysis on tissue microarrays. Histopathology 2006;48:149-156.

29 Peiro G, Mayr D, Hillemanns P, et al. Analysis of HER-2/neu amplification in endometrial carcinoma by chromogenic in situ hybridization. Correlation with fluorescence in situ hybridization, HER-2/neu, p53 and Ki-67 protein expression, and outcome. Mod Pathol 2004;17:227-287.

30 Montironi R, Mazzucchelli R, Barbisan F, et al. HER2 expression and gene amplification in pT2a Gleason score 6 prostate cancer incidentally detected in cystoprostatectomies. Comparison with clinically detected androgen dependent and independent cancer. Human Pathol 2006;37:1137-1144.

31 Kitamura Y, Hirotab S. Kit as a human oncogenic tyrosine kinase. Cell Mol Life Sci 2004;61:2924-2931.

32 Sawyer EJ, Poulsom R, Hunt FT, et al. Malignant phyllodes tumours show stromal overexpression of c-myc and c-kit. J Pathol 2003;200:59-64. 